\title{
Bladder cancer: modeling and translation
}

\author{
Jonathan E. Rosenberg ${ }^{1,4}$ and William C. Hahn ${ }^{1,2,3}$ \\ ${ }^{1}$ Department of Medical Oncology, Dana-Farber Cancer Institute, Boston, Massachusetts 02115, USA; ${ }^{2}$ Broad Institute of \\ Harvard and Massachusetts Institute of Technology, Cambridge, Massachusetts 02142, USA
}

Transitional cell carcinoma of the bladder is a common malignancy worldwide that is associated with significant morbidity and mortality. Although superficial tumors can often be treated effectively, invasive cancers not only require invasive surgery, but are also refractory to aggressive chemotherapy and radiotherapy. In this issue of Genes \& Development, Puzio-Kuter and colleagues (pp. 675-680) describe an elegant genetically engineered murine model of bladder cancer that recapitulates many of the cardinal features of the human disease. The development of such models together with the application of new approaches to enumerate the complement of genetic alterations in bladder will provide new insights into the molecular nature of this disease. Moreover, the anatomy of this urinary malignancy provides a unique opportunity for innovative translational studies.

\section{Clinical features}

The incidence of bladder cancer continues to increase; in 2008 , bladder cancer was diagnosed in 68,000 patients and was the proximal cause of 14,000 deaths in the U.S. (Jemal et al. 2008). Overall, bladder cancer is the fourth most common cancer in men and the ninth most common cancer in women. The majority of bladder cancers diagnosed in highly developed countries is of transitional cell (urothelial) histology. Although the majority of patients with bladder cancer are diagnosed with a superficial, low-grade, and noninvasive disease, $\sim 30 \%$ of patients present with high-grade or invasive or metastatic disease. The risk of distant metastasis, the lethal phenotype of bladder cancer, increases dramatically with invasion of the deep muscle layer of the bladder wall.

Superficial bladder cancers are treated by local excision. Although this approach is highly effective in eradicating an existing tumor, tumor recurrence occurs in more than $30 \%$ of cases. For this reason, surgery for superficial lesions is often followed by intravesicular

[Keywords: Bladder cancer; mTOR signaling; mouse models; preclinical trials; rapamycin; tissue microarrays]

Correspondence.

${ }^{3}$ E-MAIL William_Hahn@dfci.harvard.edu; FAX (617) 632-4005.

${ }^{4}$ E-MAIL Jonathan_Rosenberg@dfci.harvard.edu; FAX (617) 632-2165.

Article is online at http://www.genesdev.org/cgi/doi/10.1101/gad.1789109. infusion of adjuvant therapy. The most commonly used agents include Bacillus Calmette-Guerin (BCG), mitomycin $\mathrm{C}$, thiotepa, and doxorubicin. Although derived empricially, the rationale of these therapies are to provide direct exposure of the urothelium to these agents and decrease local recurrence. Unfortunately despite these treatments, a significant number of patients experience recurrent and progressive disease.

Radical cystectomy is the standard therapy in the United States for patients with muscle-invasive urothelial carcinoma of the bladder. This surgery consists of the removal of the bladder, prostate, seminal vesicles, and perivesical tissues in men, and removal of the bladder, uterus, fallopian tubes, and anterior vaginal wall in women. Lymphadenectomy, as part of definitive surgery, has become the standard of care and plays a prognostic and possibly therapeutic role in this disease (Stein et al. 2003; Herr et al. 2004; Sanderson et al. 2004). Despite advances in imaging technology, $21 \%$ and $15 \%$ of lymph node metastases cannot be detected by CT or MRI, respectively (Persad et al. 1993; Paik et al. 2000). FDGPET imaging has not yet proven its value in accurate staging for muscle-invasive disease, in part due to the excretion of tracer in the urine making evaluation of pelvic lymph nodes difficult.

Even with optimal surgical management including lymph node dissection, approximately fifty percent of patients with muscle-invasive disease will relapse and die of their disease. Most patients who recur after cystectomy relapse with distant metastases, although local recurrences occur in about $30 \%$ of relapsed patients (Frank et al. 2003; Madersbacher et al. 2003).

Survival in muscle-invasive bladder cancer is highly dependent on pathologic stage. For patients with disease confined to the bladder (pathologic T2 disease), 5-yr survival is $\sim 60 \%-70 \%$. This number declines in patients with extravesical extension. Patients with pathologic T3 disease (through the detrusor muscle, and/or extension outside the bladder) have a 5 -yr survival of $\sim 36 \%-58 \%$, while patients with adjacent organ invasion (pathologic T4) or nodal involvement experience relapse at a very high frequency. This stage-dependent survival reduction is due to the presence of micrometastases at the time of cystectomy.

Treatment of metastatic bladder cancer with combination cisplatin-based chemotherapy yields improved median overall survival, and occasional cures in patients 
with lymph-node only metastatic disease. This chemosensitivity provides the rationale for employing perioperative (neoadjuvant and/or adjuvant) chemotherapy to reduce the incidence of distant metastases and to improve cure rates. Two well-conducted randomized phase III studies have demonstrated a modest improvement $(5 \%-6 \%$ increase in overall survival at $5 \mathrm{yr})$ in median survival with preoperative combination cisplatin-based chemotherapy followed by radical cystectomy compared with cystectomy alone (International Collaboration of Trialists 1999; Grossman et al. 2003; Vale 2005). Randomized studies of adjuvant chemotherapy have not confirmed a survival benefit for post-operative chemotherapy, although many of these studies were statistically flawed and closed prematurely (Vale 2006).

Median survival in patients with locally advanced unresectable or metastatic bladder cancer remains 9-20 mo, and the addition of other cytotoxic agents to current multiagent chemotherapy regimens are unlikely to improve outcomes substantially. Thus, the most significant breakthroughs are likely to be derived from understanding the biology of these aggressive tumors.

\section{Bladder cancer genetics}

Superficial, low-grade bladder cancer appears to arise via different molecular pathways than high-grade and muscleinvasive bladder cancer. Low-grade papillary tumors frequently demonstrate activation of the FGFR3 and HRAS proto-oncogenes (Czerniak et al. 1992; Knowles 2007). Many muscle-invasive tumors arise from preexisting urothelial carcinoma in situ, a high-grade intraepithelial neoplasm and often exhibit alterations in the TP53, RB, and PTEN tumor suppressor genes (Table 1). However, since such tumors exhibit many karyotypic alterations, it is likely that additional mutations in oncogenes and tumor suppressor genes are involved in the transition from in situ tumors to invasive tumors.

Deletion or mutations of the TP53 locus on chromosome $17 \mathrm{p} 13$ occurs frequently in urothelial carcinoma in situ. Mutation in TP53 not only disrupts its function, but also prevents normal ubiquitination, leading to nuclear accumulation of $\mathrm{p} 53$ protein that can be detected immun- histochemically (Esrig et al. 1993; Cordon-Cardo et al. 1994). This nuclear p53 staining is predictive of poor outcome in patients with invasive disease (Esrig et al. 1994; Schmitz-Dräger et al. 2000). For patients with invasive bladder cancer, recurrence rates for pathologic T1 (pT1) (lamina propria-invasive), pT2 (muscle-invasive), and pT3 (microscopic extension outside the bladder) tumors without detectable nuclear p53 reactivity were $7 \%, 12 \%$, and $11 \%$, compared with $62 \%, 56 \%$, and $80 \%$ for tumors that showed p53 immunoreactivity. Although there is significant concordance between p53 mutation and nuclear accumulation, several studies have suggested that nuclear accumulation can occur in the absence of mutation. The exact details of the relationship between nuclear accumulation and point mutation have yet to be fully elucidated.

Other p53 target proteins appear to play a role in the prognosis and progression of bladder cancer. Loss of p21, a downstream effector of p53 (el-Deiry et al. 1993), leads to increased cyclin levels and cell cycle progression. Furthermore, similar to p53 mutations, loss of p21 expression is a marker for increased risk of bladder cancer progression to invasive or advanced disease. Conversely, p21 expression appears to reduce the effect of p53 loss (Stein et al. 1998). In addition, MDM2, which regulates p53 protein levels, is frequently overexpressed in bladder cancer, particularly low- and intermediate-grade tumors (Lianes et al. 1994).

Deletions and rearrangements of chromosome 13q also occur at high frequency in bladder cancer and are associated with disruption of the $R B$ gene. $R B$ is inactivated by mutation, hyperphosphorylation, as well as deletion in urothelial carcinoma (Chatterjee et al. 2004b). Disruption of $R B$ is associated with a poor prognosis and more aggressive disease (Cordon-Cardo et al. 1992).

Accumulation of alterations in TP53, RB, p21, MDM2, and p16 has been demonstrated to be predictive of outcomes in several retrospective studies. In one study, tumor specimens were characterized on the basis of the presence of altered p53, RB, or p21. The presence of one or more alterations resulted in stepwise reduction in 5-yr recurrence rates and survival, which was independent of tumor stage (Chatterjee et al. 2004a). Other studies have

Table 1. Major recurrent genetic alterations in bladder cancer

\begin{tabular}{|c|c|c|}
\hline Gene & Alterations & Impact \\
\hline TP53 & $\begin{array}{l}\text { Deletion, mutation, altered protein localization, } \\
\text { protein accumulation }\end{array}$ & Associated with high-grade, invasive disease \\
\hline$R B$ & Deletion, mutation, hyperphosphorylation & Associated with high-grade, invasive disease \\
\hline PTEN & $\begin{array}{l}\text { Deletion, mutation, decreased protein expression, } \\
\text { promoter hypermethylation }\end{array}$ & Associated with poor outcomes \\
\hline$A K T 1$ & Activation by phosphorylation & Low-stage disease \\
\hline PIK3CA & Activating mutation, overexpression & Low-grade/low-stage \\
\hline FGFR3 & Activating mutation & Associated with low-grade, low-stage disease \\
\hline$H R A S$ & Mutation, up-regulation & Unclear significance \\
\hline $\mathrm{p} 16(I N K 4 A)$ & Homozygous deletion, rarely mutation & High recurrence risk \\
\hline $\mathrm{p} 21(C D K N 2 A)$ & Deletion, mutation & $\begin{array}{l}\text { Associated with disease progression } \\
\text { and poor disease-specific survival }\end{array}$ \\
\hline$M D M 2$ & Overexpression, amplification & May attenuate effect of p53 alteration \\
\hline
\end{tabular}


evaluated other markers such as p16 and MDM2 in combination with $\mathrm{p} 53, \mathrm{RB}$, and $\mathrm{p} 21$ and found similar results (Lu et al. 2002; Shariat et al. 2004). Taken together, these studies provide strong evidence that disruption of $T P 53$ and $R B$ play important roles in invasive bladder cancers through their roles in regulating cell cycle progression and cell survival.

The PTEN/AKT pathway has also been implicated in muscle-invasive bladder cancer. Preclinical evidence suggests that restoration of PTEN function induces growth arrest in bladder cancer cell lines deficient in PTEN, and inhibition of phosphatidylinositol 3' kinase (PI3K) may decrease the invasive potential of bladder tumors (Tanaka et al. 2000; Wu et al. 2004). In this issue of Genes \& Development, Puzio-Kuter et al. (2009) demonstrate that decreased PTEN staining is frequent in advanced bladder tumors, and this loss was associated with increased levels of phospho-AKT. Both phosphorylated AKT and PTEN loss were found to be significant independent predictors of overall survival in this patient population. Furthermore, in this study, the presence of PTEN loss and TP53 mutation identified a subgroup with particularly poor outcomes.

Although HRAS was first identified as an oncogene in bladder cancer cell lines, the precise relationship between HRAS mutation and bladder cancer remains unclear. The frequency of $H R A S$ mutations ranges from $0 \%$ to $84 \%$ (Knowles and Williamson 1993; Cerutti et al. 1994; Saito et al. 1997). While HRAS mutation may not be critical for tumorigenesis, the RAS pathway clearly plays a role, particularly due to upstream activation of receptor tyrosine kinases such as FGFR3 (Ye et al. 1993; Vageli et al. 1996). Activating mutations in FGFR3 are frequently found in a high proportion of superficial bladder cancers, and a smaller proportion of invasive bladder cancers (van Rhijn et al. 2004). Whether these mutations drive progression in invasive tumors is unclear.

\section{Experimental models}

Several established cancer cell lines derived from human bladder tumors have been used as experimental models for bladder cancer. Indeed, one of the first human oncogenes, $H R A S$, was identified as a transforming gene from the T24 bladder carcinoma cell line (Shih and Weinberg 1982; Taparowsky et al. 1982). Orthotopic implantation of human bladder cancer cell lines recapitulates some of the features of the cancers from which such cells were derived and has been used as an experimental model to test drug combinations preclinically (Theodorescu et al. 1990; Watanabe et al. 2000). However, such methods are relatively inefficient and require the use of immunodeficient animals.

In this issue of Genes \& Development, Puzio-Kuter et al. (2009) exploit the known genetics of invasive bladder cancer together with intravesicular injection of a recombinant adenovirus encoding Cre recombinase to create an experimental model of human bladder cancer in the mouse. Specifically, they tested the consequences of deleting pairwise combinations of the $R B, T P 53$, and
PTEN tumor suppressor genes in the urothelium and only found tumors in animals where both TP53 and PTEN were deleted. The highly penetrant tumors found in these animals resembled highly invasive bladder carcinomas and were both locally invasive and metastatic. In consonance with these observations, they found that human bladder carcinomas that exhibited evidence of inactivation of both PTEN and TP53 pathways were associated with a significantly worse prognosis, recapitulating findings in human patients.

Prior work has shown that inactivation of PTEN leads to activation of the PI3K signaling pathway including the TOR kinase (Carracedo and Pandolfi 2008). Using transplanted tissue recombinants derived from bladder tumors in which TP53 and PTEN were deleted, Puzio-Kuter et al. (2009) showed that treatment with the TOR inhibitor rapamycin slowed cell proliferation and tumor growth. These studies not only provide preclinical evidence that TOR inhibitors may show beneficial effects in bladder tumors that lack expression of PTEN, but also demonstrate how this model may be useful for the study of other potential therapeutic regimens.

\section{Translational opportunities}

The experimental model described in this issue provides an important new tool in studying the biology of transitional cell cancers. Indeed, one question raised by these studies is the role of $R B$ loss in bladder cancer development. Does $R B$ loss cooperate with PTEN and TP53 loss or are $R B$-deficient tumors a different subclass of bladder cancers? Although further studies using models such as the ones described by Puzio-Kuter et al. (2009) will be required to answer these questions, the relative ease in which tumors with the desired genotypes can be created in situ will undoubtedly accelerate such studies.

In addition, the rapid implementation of technologies to interrogate cancer genomes should permit a more complete understanding of the genetic alterations that occur in both superficial and invasive bladder cancers. As has been found already in glioblastomas (The Cancer Genome Atlas Research Network 2008) and lung cancers (Weir et al. 2007; Ding et al. 2008), analysis of copy number alterations and mutations in large numbers of tumors provides invaluable insights into the pathways altered in particular tumor types. Since cystoscopy is performed in nearly all patients with bladder tumors (both superficial and invasive), there is an unmatched opportunity to obtain high quality tumor material in a manner suitable for such studies.

Such studies will provide a framework for the development and refinement of the genetically engineered bladder model described here. The rapidly increasing repertoire of genetically engineered mice harboring alleles that can be conditionally activated or deleted will permit the rapid development of genetically engineered models of bladder cancer. Moreover, when combined with clinicopathological studies as in this study, such studies will not only identify mutations critical bladder cancer phenotypes, but will also identify patient populations for targeted clinical studies. 
Moreover, since neoadjuvant trials have long been used as a method to try to preserve bladder function, there is the opportunity to perform preclinical studies in either xenograft or genetically engineered experimental models in a manner analogous to human clinical studies. Such studies promise not only to accelerate the identification of better treatment regimens for invasive bladder cancers, but will also serve as a model for translational studies in other epithelial cancers.

\section{References}

The Cancer Genome Atlas Research Network. 2008. Comprehensive genomic characterization defines human glioblastoma genes and core pathways. Nature 455: 1061-1068.

Carracedo, A. and Pandolfi, P.P. 2008. The PTEN-PI3K pathway: Of feedbacks and cross-talks. Oncogene 27: 5527-5541.

Cerutti, P., Hussain, P., Pourzand, C., and Aguilar, F. 1994. Mutagenesis of the H-ras protooncogene and the p53 tumor suppressor gene. Cancer Res. 54: 1934s-1938s.

Chatterjee, S.J., Datar, R., Youssefzadeh, D., George, B., Goebell, P.J., Stein, J.P., Young, L., Shi, S.R., Gee, C., Groshen, S., et al. 2004a. Combined effects of p53, p21, and pRb expression in the progression of bladder transitional cell carcinoma. J. Clin. Oncol. 22: 1007-1013.

Chatterjee, S.J., George, B., Goebell, P.J., Alavi-Tafreshi, M., Shi, S.R., Fung, Y.K., Jones, P.A., Cordon-Cardo, C., Datar, R.H., and Cote, R.J. 2004b. Hyperphosphorylation of pRb: A mechanism for RB tumour suppressor pathway inactivation in bladder cancer. J. Pathol. 203: 762-770.

Cordon-Cardo, C., Wartinger, D., Petrylak, D., Dalbagni, G., Fair, W.R., Fuks, Z., and Reuter, V.E. 1992. Altered expression of the retinoblastoma gene product: Prognostic indicator in bladder cancer. J. Natl. Cancer Inst. 84: 1251-1256.

Cordon-Cardo, C., Dalbagni, G., Saez, G.T., Oliva, M.R., Zhang, Z.F., Rosai, J., Reuter, V.E., and Pellicer, A. 1994. p53 mutations in human bladder cancer: Genotypic versus phenotypic patterns. Int. J. Cancer 56: 347-353.

Czerniak, B., Cohen, G.L., Etkind, P., Deitch, D., Simmons, H., Herz, F., and Koss, L.G. 1992. Concurrent mutations of coding and regulatory sequences of the Ha-ras gene in urinary bladder carcinomas. Hum. Pathol. 23: 1199-1204.

Ding, L., Getz, G., Wheeler, D.A., Mardis, E.R., McLellan, M.D., Cibulskis, K., Sougnez, C., Greulich, H., Muzny, D.M., Morgan, M.B., et al. 2008. Somatic mutations affect key pathways in lung adenocarcinoma. Nature 455: 1069-1075.

el-Deiry, W.S., Tokino, T., Velculescu, V.E., Levy, D.B., Parsons, R., Trent, J.M., Lin, D., Mercer, W.E., Kinzler, K.W., and Vogelstein, B. 1993. WAF1, a potential mediator of $\mathrm{p} 53$ tumor suppression. Cell 75: 817-825.

Esrig, D., Spruck, C.H., Nichols, P.W., Chaiwun, B., Steven, K., Groshen, S., Chen, S.C., Skinner, D.G., Jones, P.A., and Cote, R.J. 1993. p53 nuclear protein accumulation correlates with mutations in the p53 gene, tumor grade, and stage in bladder cancer. Am. J. Pathol. 143: 1389-1397.

Esrig, D., Elmaiian, D., Groshen, S., Freeman, J.A., Stein, J.P., Chen, S.-C., Nichols, P.W., Skinner, D.G., Jones, P.A., and Cote, R.J. 1994. Accumulation of nuclear p53 and tumor progression in bladder cancer. N. Engl. J. Med. 331: 12591264.

Frank, I., Cheville, J.C., Blute, M.L., Lohse, C.M., Nehra, A., Weaver, A.L., Karnes, R.J., and Zincke, H. 2003. Transitional cell carcinoma of the urinary bladder with regional lymph node involvement treated by cystectomy: Clinicopathologic features associated with outcome. Cancer 97: 2425-2431.
Grossman, H.B., Natale, R.B., Tangen, C.M., Speights, V.O., Vogelzang, N.J., Trump, D.L., deVere White, R.W., Sarosdy, M.F., Wood Jr., D.P., Raghavan, D., et al. 2003. Neoadjuvant chemotherapy plus cystectomy compared with cystectomy alone for locally advanced bladder cancer. N. Engl. J. Med. 349: 859-866.

Herr, H.W., Faulkner, J.R., Grossman, H.B., Natale, R.B., deVere White, R., Sarosdy, M.F., and Crawford, E.D. 2004. Surgical factors influence bladder cancer outcomes: A cooperative group report. J. Clin. Oncol. 22: 2781-2789.

International Collaboration of Trialists on behalf of the Medical Research Council, Advanced Bladder Cancer Working Party, EORTC Genito-Urinary Group, Australian Bladder Cancer Study Group, National Cancer Institute of Canada Clinical Trials Group, Finnbladder, Norwegian Bladder Cancer Study Group, and Club Urologico Espanol de Tratamiento Oncologico (CUETO) group 1999. Neoadjuvant cisplatin, methotrexate, and vinblastine chemotherapy for muscle-invasive bladder cancer: A randomised controlled trial. Lancet 354: 533-540.

Jemal, A., Siegel, R., Ward, E., Hao, Y., Xu, J., Murray, T., and Thun, M.J. 2008. Cancer Statistics, 2008. CA Cancer J. Clin. 58: 71-96.

Knowles, M.A. 2007. Role of FGFR3 in urothelial cell carcinoma: Biomarker and potential therapeutic target. World $J$. Urol. 25: 581-593.

Knowles, M.A. and Williamson, M. 1993. Mutation of H-ras is infrequent in bladder cancer: Confirmation by single-strand conformation polymorphism analysis, designed restriction fragment length polymorphisms, and direct sequencing. Cancer Res. 53: 133-139.

Lianes, P., Orlow, I., Zhang, Z.F., Oliva, M.R., Sarkis, A.S., Reuter, V.E., and Cordon-Cardo, C. 1994. Altered patterns of MDM2 and TP53 expression in human bladder cancer. $J$. Natl. Cancer Inst. 86: 1325-1330.

Lu, M.-L., Wikman, F., Orntoft, T.F., Charytonowicz, E., Rabbani, F., Zhang, Z., Dalbagni, G., Pohar, K.S., Yu, G., and Cordon-Cardo, C. 2002. Impact of alterations affecting the p53 pathway in bladder cancer on clinical outcome, assessed by conventional and array-based methods. Clin. Cancer Res. 8: $171-179$.

Madersbacher, S., Hochreiter, W., Burkhard, F., Thalmann, G.N., Danuser, H., Markwalder, R., and Studer, U.E. 2003. Radical cystectomy for bladder cancer today-a homogeneous series without neoadjuvant therapy. J. Clin. Oncol. 21: 690-696.

Paik, M.L., Scolieri, M.J., Brown, S.L., Spirnak, J.P., and Resnick, M.I. 2000. Limitations of computerized tomography in staging invasive bladder cancer before radical cystectomy. $J$. Urol. 163: 1693-1696.

Persad, R., Kabala, J., Gillatt, D., Penry, B., Gingell, J.C., and Smith, P.J. 1993. Magnetic resonance imaging in the staging of bladder cancer. Br. J. Urol. 71: 566-573.

Puzio-Kuter, A.M., Castillo-Martin, M., Kinkade, C.W., Wang, X., Shen, T.H., Matos, T., Shen, M.M., Cordon-Cardo, C., and Abate-Shen, C. 2009. Inactivation of $p 53$ and Pten promotes invasive bladder cancer. Genes \& Dev. (this issue). doi: 10.1101/gad.1772909.

Saito, S., Hata, M., Fukuyama, R., Sakai, K., Kudoh, J., Tazaki, H., and Shimizu, N. 1997. Screening of H-ras gene point mutations in 50 cases of bladder carcinoma. Int. J. Urol. 4: 178-185.

Sanderson, K.M., Stein, J.P., and Skinner, D.G. 2004. The evolving role of pelvic lymphadenectomy in the treatment of bladder cancer. Urol. Oncol. 22: 205-211.

Schmitz-Dräger, B.J., Goebell, P.J., and Heydthausen, M. 2000. p53 immunohistochemistry in bladder cancer: Combined analysis: A way to go? Urol. Oncol. 5: 204-210. 
Shariat, S.F., Tokunaga, H., Zhou, J., Kim, J., Ayala, G.E., Benedict, W.F., and Lerner, S.P. 2004. p53, p21, pRB, and p16 expression predict clinical outcome in cystectomy with bladder cancer. J. Clin. Oncol. 22: 1014-1024.

Shih, C. and Weinberg, R.A. 1982. Isolation of a transforming sequence from a human bladder carcinoma cell line. Cell 29: 161-169.

Stein, J.P., Ginsberg, D.A., Grossfeld, G.D., Chatteriee, S.J., Esrig, D., Dickinson, M.G., Groshen, S., Taylor, C.R., Jones, P.A., Skinner, D.G., et al. 1998. Effect of p21WAF1/CIP1 expression on tumor progression in bladder cancer. J. Natl. Cancer Inst. 90: 1072-1079.

Stein, J.P., Cai, J., Groshen, S., and Skinner, D.G. 2003. Risk factors for patients with pelvic lymph node metastases following radical cystectomy with en bloc pelvic lymphadenectomy: Concept of lymph node density. J. Urol. 170: 35-41.

Tanaka, M., Koul, D., Davies, M.A., Liebert, M., Steck, P.A., and Grossman, H.B. 2000. MMAC1/PTEN inhibits cell growth and induces chemosensitivity to doxorubicin in human bladder cancer cells. Oncogene 19: 5406-5412.

Taparowsky, E., Suard, Y., Fasano, O., Shimizu, K., Goldfarb, M., and Wigler, M. 1982. Activation of the T24 bladder carcinoma transforming gene is linked to a single amino acid change. Nature 300: 762-765.

Theodorescu, D., Cornil, I., Fernandez, B.J., and Kerbel, R.S. 1990. Overexpression of normal and mutated forms of HRAS induces orthotopic bladder invasion in a human transitional cell carcinoma. Proc. Nat1. Acad. Sci. 87: 9047-9051.

Vageli, D., Kiaris, H., Delakas, D., Anezinis, P., Cranidis, A., and Spandidos, D.A. 1996. Transcriptional activation of H-ras, Kras and $\mathrm{N}$-ras proto-oncogenes in human bladder tumors. Cancer Lett. 107: 241-247.

Vale, C.L. 2005. Neoadjuvant chemotherapy in invasive bladder cancer: Update of a systematic review and meta-analysis of individual patient data advanced bladder cancer $(\mathrm{ABC})$ metaanalysis collaboration. Eur. Urol. 48: 202-205.

Vale, C. 2006. Adjuvant chemotherapy for invasive bladder cancer (individual patient data). Cochrane Database Syst. Rev. CD006018. doi: 10.1002/14651858.CD006018.

van Rhijn, B.W., van der Kwast, T.H., Vis, A.N., Kirkels, W.J., Boeve, E.R., Jobsis, A.C., and Zwarthoff, E.C. 2004. FGFR3 and P53 characterize alternative genetic pathways in the pathogenesis of urothelial cell carcinoma. Cancer Res. 64: 1911-1914.

Watanabe, T., Shinohara, N., Sazawa, A., Harabayashi, T., Ogiso, Y., Koyanagi, T., Takiguchi, M., Hashimoto, A., Kuzumaki, N., Yamashita, M., et al. 2000. An improved intravesical model using human bladder cancer cell lines to optimize gene and other therapies. Cancer Gene Ther. 7: 1575-1580.

Weir, B.A., Woo, M.S., Getz, G., Perner, S., Ding, L., Beroukhim, R., Lin, W.M., Province, M.A., Kraja, A., Johnson, L.A., et al. 2007. Characterizing the cancer genome in lung adenocarcinoma. Nature 450: 893-898.

Wu, X., Obata, T., Khan, Q., Highshaw, R.A., de Vere White, R., and Sweeney, C. 2004. The phosphatidylinositol-3 kinase pathway regulates bladder cancer cell invasion. BJU Int. 93: 143-150.

Ye, D.W., Zheng, J.F., Qian, S.X., and Ma, Y.J. 1993. Correlation between the expression of oncogenes ras and c-erbB-2 and the biological behavior of bladder tumors. Urol. Res. 21: 39-43. 


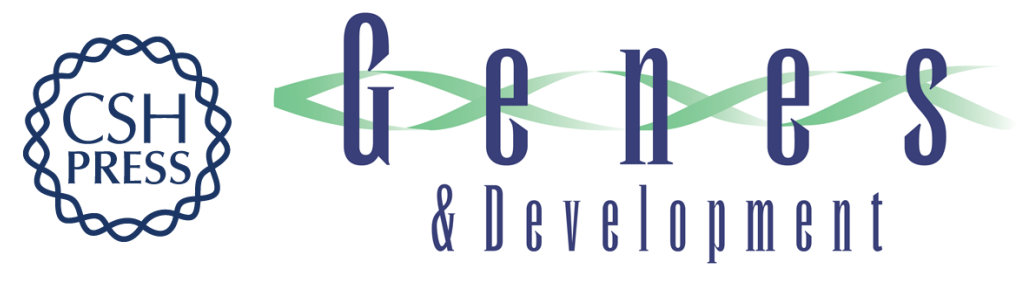

\section{Bladder cancer: modeling and translation}

Jonathan E. Rosenberg and William C. Hahn

Genes Dev. 2009, 23:

Access the most recent version at doi:10.1101/gad.1789109

\section{Related Content}

References License
Inactivation of p53 and Pten promotes invasive bladder cancer Anna M. Puzio-Kuter, Mireia Castillo-Martin, Carolyn W. Kinkade, et al. Genes Dev. March , 2009 23: 675-680

This article cites 42 articles, 10 of which can be accessed free at: http://genesdev.cshlp.org/content/23/6/655.full.html\#ref-list-1

Articles cited in: http://genesdev.cshlp.org/content/23/6/655.full.html\#related-urls

\section{Email Alerting Service \\ License}

Receive free email alerts when new articles cite this article - sign up in the box at the top right corner of the article or click here.

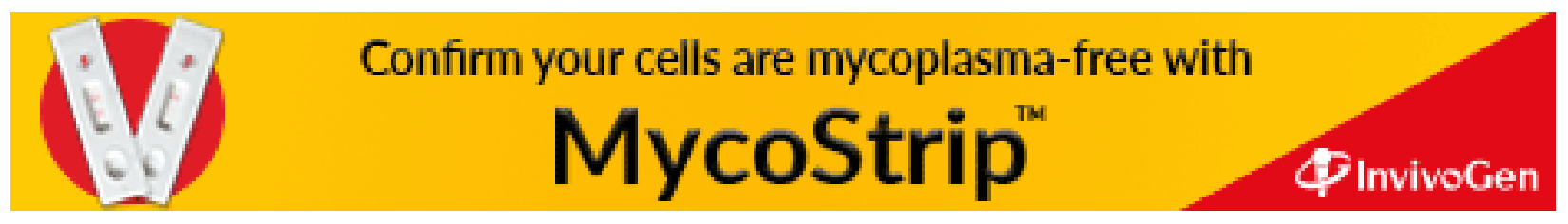

